\title{
A Renewed Call to Smoking Cessation in the Era of the COVID-19 Pandemic
}

\author{
Moronkeji Fagbemi, MD'1,2
}

$\mathrm{T}$ obacco smoking remains the No. 1 preventable cause of death, accounting for approximately 480,000 deaths annually in the United States. Approximately 40 million adults in the United States are current smokers. ${ }^{1}$

Cigarette smoking is a significant cause of cardiovascular and respiratory disease morbidity and mortality. Smoking is a significant risk factor for diabetes, with smokers approximately $40 \%$ more likely to develop type 2 diabetes than nonsmokers. ${ }^{2}$ Chronic smoking is associated with elevated blood pressure, coronary artery disease, chronic lung disease, increased respiratory infections, worsening asthma, and worsening pulmonary function, all of which appear from early data to be significant risk factors for complicated SAR-CoV-2 infection with resulting COVID-19..$^{3-5}$

For the fortunate patients with a history of chronic cigarette smoking use disorder who have been discharged from the hospital after treatment for complicated COVID-19 infection, as well as those without the disease who are worried about the deleterious effects of smoking on their lungs, now more than

\section{AFFILIATIONS:}

${ }^{1}$ Assistant Professor of Medicine, Icahn School of Medicine at Mount Sinai, New York, New York

${ }^{2}$ Unit Chief, Inpatient Detoxification Unit, Departments of Medicine and Psychiatry, BronxCare Health System, Bronx, New York

\section{CITATION:}

Fagbemi M. A renewed call to smoking cessation in the era of the COVID-19 pandemic. Consultant. 2020;60(7):e5. doi:10.25270/con.2020.04.00017 Received April 15, 2020. Accepted April 21, 2020.

\section{DISCLOSURES:}

The author reports no relevant financial relationships.

\section{ADDITIONAL CONTRIBUTIONS:}

The author thanks Anna Fagbemi at the City University of New York School of Medicine/Sophie Davis Biomedical Education Program for her valuable suggestions during preparation of the manuscript in the area of evaluating readiness for smoking cessation.

\section{CORRESPONDENCE:}

Moronkeji Fagbemi, MD, 1285 Life Recovery Center, BronxCare Hospital, 1285 Fulton Ave, Bronx, NY 10456 (mfagbemi@bronxcare.org) ever clinicians are in a unique position to evaluate and assist these patients with evidence-based techniques and treatments on their way to tobacco smoking cessation.

\section{STEP 1: PROBLEM IDENTIFICATION}

The road to helping a patient quit smoking usually begins with an accurate identification of the problem and its severity. This can be quickly and effectively achieved with the use of a standardized questionnaire such as the Fagerström Test for Nicotine Dependence, ${ }^{6}$ consisting of 6 short questions that can easily be completed within a minute, whether in the hospital, in a medical office, or via telemedicine. These questions touch on important aspects such as, "How soon after waking up does a patient smoke?", "How difficult is it to refrain from smoking in places with restrictions, such as houses of worship?", "Which cigarette is treasured more-early morning or later in the day?", to mention a few. The maximum score for the questionnaire is 10 points. A score of 7 to 10 points denotes high dependence, a score of 4 to 6 denotes moderate dependence, and a score below 4 denotes mild dependence (Figure 1).

\section{STEP 2: EVALUATION OF REASONS FOR SMOKING AND BARRIERS TO CESSATION}

The next step is usually trying to understand why the patient smokes and finds smoking reinforcing. This involves asking open-ended questions, since every patient is unique. This aspect of the evaluation can be accomplished by also touching on the known reasons for cigarette smoking, such as for stress and emotional tension relief,' alleviation of depressed mood, alleviation of sleep problems, weight control, having a sense of belonging in a group, or simply for sensory rewards. A brief evaluation for psychiatric comorbidities is important, since these patients tend to have an increased rate of smoking compared with the general population. ${ }^{8}$

Most patients have tried quitting several times, either by themselves or with some medical assistance; therefore, inquiring with short but focused discussion of known barriers such as misconceptions about smoking as an addictive disease rather than a moral weakness, the persistence of unbearable physical symptoms of withdrawal in previous quit attempts, the pressures from sociocultural norms and factors, ${ }^{9}$ limited accessibility to assisted smoking cessation in the past, and successful quit attempts 


\section{A Renewed Call to Smoking Cessation in the Era of the COVID-19 Pandemic}

\begin{tabular}{|c|c|c|c|}
\hline & Questions & Patient Response & Score \\
\hline \multirow[t]{4}{*}{1} & \multirow{4}{*}{$\begin{array}{l}\text { How soon after you wake } \\
\text { up do you smoke your } \\
\text { first cigarette? }\end{array}$} & After 60 minutes & 0 \\
\hline & & 31-60 minutes & 1 \\
\hline & & 6-30 minutes & 2 \\
\hline & & Within 5 minutes & 3 \\
\hline \multirow[t]{2}{*}{2} & \multirow{2}{*}{$\begin{array}{l}\text { Do you find it difficult to } \\
\text { refrain from smoking in } \\
\text { places where it is forbid- } \\
\text { den such as churches, at } \\
\text { the library, in the cinema? }\end{array}$} & No & 0 \\
\hline & & Yes & 1 \\
\hline \multirow[t]{2}{*}{3} & \multirow[t]{2}{*}{$\begin{array}{l}\text { Which cigarette would } \\
\text { you hate most to give up? }\end{array}$} & $\begin{array}{l}\text { The first one in } \\
\text { the morning } \\
\end{array}$ & 1 \\
\hline & & Any other & 0 \\
\hline \multirow[t]{4}{*}{4} & \multirow{4}{*}{$\begin{array}{l}\text { How many cigarettes per } \\
\text { day do you smoke? }\end{array}$} & 10 or less & 0 \\
\hline & & $11-20$ & 1 \\
\hline & & $21-30$ & 2 \\
\hline & & 31 or more & 3 \\
\hline \multirow[t]{2}{*}{5} & \multirow{2}{*}{$\begin{array}{l}\text { Do you smoke more } \\
\text { frequently during the first } \\
\text { hours after waking than } \\
\text { during the rest of the } \\
\text { day? }\end{array}$} & No & 0 \\
\hline & & Yes & 1 \\
\hline \multirow[t]{2}{*}{6} & \multirow{2}{*}{$\begin{array}{l}\text { Do you smoke when you } \\
\text { are so ill that you are in } \\
\text { bed most of the day? }\end{array}$} & No & 0 \\
\hline & & Yes & 1 \\
\hline \multicolumn{4}{|c|}{ Total } \\
\hline \multicolumn{4}{|c|}{$\begin{array}{l}\text { Scoring: 7-10, high dependence; 4-6, moderate depen- } \\
\text { dence; less than } 4 \text {, low dependence } \\
\text { Adapted with permission from Heatherton et al. }{ }^{6}\end{array}$} \\
\hline
\end{tabular}

Modified Fagerström Test for Nicotine Dependence

\section{2}

\section{Readiness Indicators Assessing Importance and Confidence}

\section{Importance}

How important is it to you to

On a scale of 0 to 10 , with 0 being not important \& 10 being very important..

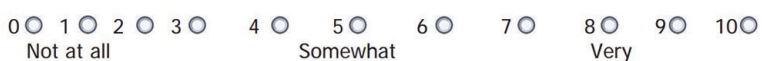

\section{Confidence}

How confident are you that you could How confident are you that you could
to 10 , with 0 being not confident at all \& 10 being very confident?

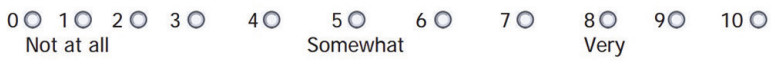

Reproduced from Dundon M. ${ }^{12}$ from previous assisted therapies. These pieces of information all vitally important in creating a comprehensive picture of the patient's tobacco use disorder.

\section{STEP 3: FOCUS ON READINESS TO QUIT}

The COVID-19 pandemic likely has generated a lot of quiet introspection among many current smokers, in turn moving many forward along the stages of behavioral change in readiness for smoking cessation.

These change stages are as follows: precontemplation, in which patients lack awareness or do not have the intention of changing their behavior; contemplation, during which patients are aware of the need for behavior change regarding smoking and are considering planning for change but have not yet committed to change; preparation, during which patients begin planning for change and are committed to following through; action, the stage of implementing intended behavior modification in an effort to change behavior; and maintenance, the stage of patients maintaining behavior change and trying to prevent termination of behavior change that can ultimately lead to a relapse. ${ }^{10,11}$

Readiness for change in behavior within patients is influenced by a blend of how important the change is to a patient and how confident they are that they can make the change. ${ }^{12} \mathrm{~A}$ useful tool to asses readiness to quit is an importance and confidence scale (Figure 2), which asks on a scale of 0 to 10 (where a score of $0-3$ is not at all important or confident, 4-6 is somewhat important or confident, and 8-10 is very important or confident), "How confident are you in quitting smoking?" While clinical experience and studies show that patients who score 7 and above are most likely to stick with the change plan, lower scores should prompt the clinician to explore the reason for the low scores. The clinician practices "rolling with resistance" to change rather than being confrontational. It also includes trying to elicit self-reflection and the patient's own concerns about the smoking problem. Every successful and lasting change has always been self-change spearheaded by the patient, then facilitated and assisted by the clinician. The clinician's approach should be empathic, nonjudgmental, nonargumentative, and supportive. ${ }^{12}$

At this junction, clinicians should also ask the patient, "What are your thoughts and feelings about quitting smoking?" This can help gauge the stage of readiness to quit, thereby deploying effective dialogue and evidence-based techniques, such as motivational interviewing, aimed at moving the patient toward the stages of action and maintenance.

Finally, all of the above, in addition to knowledge of medical and psychiatric comorbidities, ${ }^{8}$ are crucial in developing the patient's profile, including knowing what is required of the patient to successfully quit smoking, and helping to develop an individualized management plan involving self-change by the patient. In most cases, this involves the use of targeted education, counseling, and nonpharmacologic evidence-based techniques such as motivational interviewing and pharmacologic assistance 


\section{A Renewed Call to Smoking Cessation in the Era of the COVID-19 Pandemic}

on an ongoing basis with careful follow-up of the patient's response to treatment. All of these work hand-in-hand with the 5 A's of smoking cessation, namely to ask (about current smoking), advise (unequivocally to quit), assess (for reasons, barriers, and readiness to quit), assist (in moving the patient along the change process and quitting with counseling and pharmacotherapy), and arrange (for follow-up to monitor and maintain the effective process). ${ }^{13}$

\section{REFERENCES}

1. Centers for Disease Control and Prevention. Smoking and tobacco use: data and statistics. Reviewed February 18, 2020. Accessed April 21, 2020. https://www.cdc.gov/tobacco/data statistics/index.htm

2. Centers for Disease Control and Prevention, National Center for Chronic Disease Prevention and Health Promotion, Office on Smoking and Health. The Health Consequences of Smoking-50 Years of Progress: A Report of the Surgeon General. 2014. Accessed April 21, 2020. https://www.ncbi.nlm.nih. gov/books/NBK179276/pdf/Bookshelf_NBK179276.pdf

3. Onder G, Rezza G, Brusaferro S. Case-fatality rate and characteristics of patients dying in relation to COVID-19 in Italy. JAMA. Published online March 23, 2020. doi:10.1001/jama.2020.4683

4. CDC COVID-19 Response Team. Preliminary estimates of the prevalence of selected underlying health conditions among patients with coronavirus disease 2019-United States, February 12-March 28, 2020. MMWR Morb Mortal Wkly Rep. 2020;69(13):382-386. doi:10.15585/mmwr.mm6913e2

5. Liang W-h, Guan W-j, Li C-c, et al. Clinical characteristics and outcomes of hospitalised patients with COVID-19 treated in Hubei (epicenter) and outside
Hubei (non-epicenter): a nationwide analysis of China. Eur Respir J. Published online April 8, 2020. https://doi.org/10.1183/13993003.00562-2020

6. Heatherton TF, Kozlowski LT, Frecker RC, Fagerström K-O. The Fagerström Test for Nicotine Dependence: a revision of the Fagerström Tolerance Questionnaire. Br J Addict. 1991;86(9):1119-1127. doi:10.1111/j.1360-0443.1991.tb01879.x

7. Berlin I, Singleton EG, Pedarriosse A-M, et al. The Modified Reasons for Smoking Scale: factorial structure, gender effects and relationship with nicotine dependence and smoking cessation in French smokers. Addiction. 2003:98(11):1575-1583. doi:10.1046/j.1360-0443.2003.00523.x

8. Lipari RN, Van Horn S. Smoking and mental illness among adults in the United States. CBHSQ Report. March 30, 2017. Accessed April 21, 2020. https://www.ncbi.nlm.nih.gov/books/NBK430654/

9. Chean K-Y, Goh LG, Liew K-W, et al. Barriers to smoking cessation: a qualitative study from the perspective of primary care in Malaysia. BMJ Open. 2019;9(7):e025491. doi:10.1136/bmjopen-2018-025491

10. DiClemente CC, Prochaska JO, Fairhurst SK, Velicer WF, Velasquez MM, Rossi JS. The process of smoking cessation: an analysis of precontemplation, contemplation, and preparation stages of change. J Consult Clin Psychol. 1991:59(2):295-304. doi:10.1037//0022-006x.59.2.295

11. Prochaska JO, DiClemente CC. Stages and processes of self-change of smoking: toward an integrative model of change. J Consult Clin Psychol. 1983;51(3):390-395. doi:10.1037//0022-006x.51.3.390

12. Dundon M. Motivational interviewing for health behavior change. VA Health Care, Center for Integrated Healthcare. July 2013. Accessed April 21, 2020 https://www.mirecc.va.gov/cih-visn2/Documents/Provider Education_Handouts/Motivational_Interviewing_for_Health_Behavior_Change_Version_3.pdf

13. Five major steps to intervention (the " $5 A^{\prime} s$ "). Agency for Healthcare Research and Quality. Accessed April 21, 2020. https://www.ahrq.gov/sites/defaultffiles/wysiwyg/professionals/clinicians-providers/guidelines-recommendations/tobacco/5steps.pdf 